\title{
A EVOLUÇÃO DAS IDÉIAS COSMOLÓGICAS DE KANT EM SEUS ÚLTIMOS ESCRITOS
}

Jean Seidengart*

\begin{abstract}
RESUMO
Em nossa investigação, nós nos propusemos a determinar, com a maior precisão possível, a posição de Kant em face das questões de ordem cosmológica após a publicação de sua terceira Crítica. Sua correspondência reivindica expressamente as ideias cosmológicas que ele delineou em sua Teoria do céu, em 1755, e que ele decidiu reeditar várias vezes a partir da última década do século XVIII. No entanto, Kant procurou manter-se fiel à crítica das ideias cosmológicas que havia desenvolvido na Antinomia da razão pura. Essas duas intenções foram retomadas novamente na última obra que ele esboçava a partir de 1795, mas que não conseguiu concluir por conta de sua saúde em declínio. Seu objetivo era conseguir realizar o Übergang, isto é, a "ciência da passagem da metafísica da natureza à física", a qual ele mesmo dizia aos seus amigos que seria sua "obra-prima". Esse manuscrito inacabado, que a Academia de Berlim publicou sob o título Opus postumum, continha numerosas considerações físico-cosmológicas e cosmoteológicas das quais se pode restabelecer as grandes linhas. Em um primeiro momento, analisaremos a função eminente e as propriedades do "éter" ou "calórico" no Opus Postumum, a fim de entender como ele acabava de completar as considerações sobre o espaço cósmico considerado doravante por Kant expressamente como ilimitado. Em seguida, elucidaremos como Kant pretendia fazer a transição do "sistema dos elementos ao sistema do mundo", em conformidade com o plano geral do Opus Postumum, unificando o conjunto de forças motrizes que constituem o universo com a ajuda do éter. Finalmente, examinaremos como Kant passou da "metafísica das ciências da natureza" à Filosofia Transcendental para tentar concluí-la, realizando uma síntese final unificadora das três Ideias totalizadoras, que são Deus, o Mundo e o Homem, apoiando-se no tema do "Cosmotheoros", isto é, a Ideia de Homem considerado como ser
\end{abstract}

\footnotetext{
* Professor de Filosofia e Diretor do Instituto de Pesquisas Filosóficas: "As dinâmicas da invenção filosófica, científica e artística" da Universidade de Paris Oeste-Nanterre. E-mail: jean.seidengart@sfr.fr
} 
pensante e que age, mas também como um habitante do mundo. Apesar de inacabado, esse escrito tardio permite precisar como o último Kant pretendia concluir a arquitetônica de sua filosofia transcendental.

Palavras-chave: Kant. Ideias cosmológicas. Éter. Cosmotheoros. Opus postumum.

\section{RÉSUMÉ}

Dans notre investigation, nous nous proposons de déterminer aussi précisément que possible la position de Kant à l'égard des questions d'ordre cosmologique après la publication de sa troisième Critique. Sa correspondance revendique expressément les idées cosmologiques qu'il avait exposées dans sa Théorie du ciel en 1755 et qu'il décida de faire rééditer plusieurs fois à partir des dix dernières années du XVIII ${ }^{\mathrm{e}}$ siècle. Pourtant, Kant s'est efforcé de rester fidèle à la critique des idées cosmologiques qu'il avait développées dans l'Antinomie de la raison pure. Ces deux intentions furent reprises à nouveaux frais dans le dernier ouvrage qu'il ébaucha à partir de 1795 , mais qu'il ne parvint pas à achever en raison de sa santé déclinante. Son objectif était de réaliser l'Übergang c'est-à-dire la " science du passage de la Métaphysique de la nature à la physique », dont il disait lui-même à ses amis que ce serait « son chef-d'œuvre ». Ce manuscrit inachevé, que l'Académie de Berlin publia sous le titre d'Opus postumum, contenait de nombreuses considérations physico-cosmologiques et cosmothéologiques dont on peut retracer les grandes lignes. Dans un premier temps, nous analyserons la fonction éminente et les propriétés de «l'éther » ou du "calorique » dans l'Opus postumum afin de comprendre comment il venait compléter les considérations sur l'espace cosmique considéré désormais par Kant expressément comme illimité. Ensuite, nous éluciderons comment Kant comptait opérer le passage du "système des éléments au système du monde ", conformément au plan global de l'Opus postumum, en unifiant l'ensemble des forces motrices constitutives de l'univers à l'aide de l'éther. Enfin, nous examinerons comment Kant est passé de la « métaphysique des sciences de la nature » à la philosophie transcendantale pour tenter d'achever celle-ci en opérant une ultime synthèse unificatrice des trois Idées totalisatrices que sont Dieu, le Monde et l'Homme, en s'appuyant sur le thème du "Cosmotheoros », c'est-à-dire l'Idée d'Homme envisagé comme être pensant et agissant, mais aussi comme habitant du monde. Bien qu'inachevé, cet écrit tardif permet de préciser comment 
le dernier Kant entendait achever l'architectonique de sa philosophie transcendantale.

Mots clé: Kant. Idées cosmologiques. Éther. Cosmotheoros. Opus postumum.

Na medida em que Kant não publicou mais nada sobre a cosmologia desde a segunda edição da primeira Crítica, nós poderíamos imaginar que ele teria então abandonado essa questão, ou, o que é pior, que ele teria mesmo renegado a Teoria do céu de sua juventude. Mas, se nós começarmos primeiramente por examinar atentivamente sua correspondência, nós descobriremos que Kant se apega firmemente à sua concepção da Via Láctea, assim como à sua teoria dos universos-ilha, como ele se propõe a precisá-lo a um amigo, o matemático Gensichen, que reeditou em 1791 o mesmo texto da Teoria do céu. O essencial da carta precisava que, se nós separarmos o que concerne à formação do anel de Saturno e o cálculo de seu tempo de rotação:

A fim de acordar o crédito que se deve a cada um daqueles que contribuíram para a história da astronomia, desejo que adicionem um apêndice a sua obra ${ }^{1}$ para explicar o quanto minhas modestas conjecturas pessoais diferem daquelas dos teóricos ulteriores.

$1^{\circ}$ - A concepção da Via Láctea como sistema de sóis em movimento análogo ao nosso sistema planetário, eu o expus seis anos antes que Lambert publicasse uma teoria similar em suas Cartas cosmológicas. $2^{\circ}$ - A idéia de que as nebulosas são comparáveis a Vias Lácteas longínquas não foi vislumbrada por Lambert [...] porque ele as tomava por corpos obscuros (ao menos uma dentre elas) iluminados pelos sóis vizinhos. ${ }^{2}$

\footnotetext{
1 Esta obra reunia os escritos de Herschel e de Kant, a saber: W. Herschel, Sobre a constituição do céu, três relatórios traduzidas por G. M. Sommer, com um manual autêntico da História geral da natureza e Teoria do céu de Kant, Königsberg, em F. R. Nicolovius, 1791. O texto de Kant figura nas p. 163-200 e o prefácio de Gensichen está nas p. 161-162.

2 KANT, carta à Johann Friedrich Gensichen de 19 de abril de 1791, in Ak, XI, p. 252-253; e os Kant-Studien, II, 1897, p. 104 sg. Tradução nossa. Nós já encontrávamos detalhes similares na carta de KANT ao astrônomo J. E. Bode do 2 de setembro de 1790, Ak XI, 203-204; tr. fr. in Correspondance, Paris, Gallimard, 1991, p. 431: "M. Herschel descobriu para o anel de h uma rotação axial de $10 \mathrm{~h} \mathrm{22}$ ' 15", e isso a partir da partícula mais próxima
} 
Ademais, Kant se detém igualmente na sua teoria da formação dos corpos celestes que precisou e mesmo refinou desde a sua Teoria do céu e, sobretudo, desde o fim do seu artigo sobre os vulcões lunares de 1786. De fato, é sempre uma reflexão sobre a formação do anel de Saturno que lhe serve de fio condutor para explicar de modo geral a acreção ou a formação de sóis e de seu cortejo de planetas. O passo que Kant dá, para além da Teoria do céu, consiste em envolver nesta explicação não apenas a atração newtoniana (que se exerce a grande distância entre as massas), mas também a atração e as afinidades químicas que só agem a muito curta distância. É verdade que nosso filósofo acabara de descobrir a Química de Lavoisier e que doravante compreendeu que ela enfim se elevou à categoria de ciência. Essa é a razão pela qual Kant se mantém informado regularmente das descobertas científicas de seu tempo em Química, sobre o tema do calórico, do éter etc.

$\mathrm{O}$ acordo das recentes descobertas com a minha teoria no que concerne à formação do anel de Saturno a partir de uma matéria vaporosa que se move segundo as leis da força centrípeta, parece igualmente sustentar a teoria segundo a qual os grandes corpos celestes foram formados a partir das mesmas leis, exceto para o fato de que sua propriedade de rotação deve ter sido produzida originalmente pela queda dessa substância difusa causada pela gravidade. A aprovação que $\mathrm{M}$. Lichtenberg traz a essa teoria dá a ela maior força. ${ }^{3}$

da borda interna desse anel, isso poderia vir a confirmar aquilo que eu previa, há 35 anos, no meu texto História geral da natureza e Teoria do céu. [...] O modo como Monsieur Herschel representa as nebulosas, ou seja, como um sistema em si, ele mesmo incluído em um sistema, se coaduna desejavelmente com a forma que eu os expus outrora in $\mathrm{Op}$. cit., p. 14-15; este deve ser uma lacuna na memória de M. Erxleben, de atribuir, na sua física, esse pensamento a M. Lambert, que teria sido o primeiro a tê-lo, visto que suas Cartas cosmológicas apareceram 6 anos após meus escritos, e que não consigo, apesar de todas as minhas pesquisas, encontrar nelas esse tipo de representação".

3 KANT, Ibid., Ak XI, p. 253. O final desta carta afirmava: "Esta teoria é a seguinte: a matéria primitiva, espalhada no universo sob forma de vapor continha os materiais necessários a uma variedade inumerável de substâncias. No estado elástico, ela toma forma de esferas produzidas simplesmente por afinidade química das partículas que se reuniam segundo as leis da gravitação, destruindo sua elasticidade reciprocamente e constituindo assim corpos. $\mathrm{O}$ calor inerente a esses corpos seria suficiente para produzir o brilho luminoso próprio às maiores esferas (os sóis), enquanto ela se reduzia ao calor interno das esferas menores (os planetas)". 
Alguns anos mais tarde, por volta de 1795-1796, Kant começa a redação de uma obra muito importante, consagrada à "ciência da passagem [da Metafísica da natureza à Física]", na qual ele mesmo dizia ao seus amigos (entre outros a seu biógrafo Borowski) que ela seria sua "obra prima" e que ocuparia seus últimos anos de trabalho. Contudo, sabemos graças à sua correspondência que Kant já havia começado a fazer pesquisas sobre essa questão desde 1790, mas que é a necessidade de completar com prioridade a filosofia prática e a da religião que o desviou algum tempo desse vasto projeto. O manuscrito inacabado, e mesmo ainda no estado de rascunho, que Kant deixou depois de sua morte em 1804, conta mais de 1.200 páginas na edição da Academia de Berlim (1936-1938). Numerosas são as passagens em que Kant se entrega a considerações psico-cosmológicas e cosmoteológicas, mas seria extremamente temerário, da nossa parte, pretender extrair desses diversos feixes bastante desarticulados uma nova apresentação de sua cosmologia e de todos os novos desenvolvimentos sobre a questão da infinidade cósmica. Tentaremos mais modestamente dar algumas indicações sobre os últimos desenvolvimentos cosmológicos de Kant, mantendo certa reserva sobre o assunto das reais intenções de Kant, que havia formulado o desejo, segundo alguns testemunhos da época, que seu manuscrito fosse destruído, como lembra Gerhard Lehmann, em sua Introdução à edição erudita do Opus Postumum.

Num primeiro momento avaliaremos a função eminente e as propriedades do "éter" ou do "calórico" na Opus Postumum a fim de compreender como ele vinha a completar as considerações sobre o espaço cósmico considerado então por Kant expressamente como ilimitado. Em seguida, elucidaremos como Kant contava operar a passagem do "sistema dos elementos ao sistema do mundo", conforme o plano global do Opus Postumum, unificando o conjunto das forças motrizes constitutivas do universo com a ajuda do éter. Enfim, examinaremos como Kant passou da "metafísica das ciências da natureza" à filosofia transcendental para tentar concluí-la operando uma última síntese unificadora das três Ideias totalizadoras, que são Deus, o Mundo e o Homem, se apoiando na temática do "Cosmotheoros", ou seja, a ideia do homem considerado como ser pensante e atuante, mas também como habitante do mundo. Mesmo inacabado, esse escrito tardio permite precisar como o último Kant entendia concluir a arquitetônica de sua filosofia transcendental. 


\section{O problema do Übergang e o éter ilimitado}

Aparece em numerosos esboços e redações sucessivas que Kant pensava poder realizar o Übergang com a ajuda do conceito de éter, que ele chamava igualmente: "̈̈ther, Elementarstoff, Wärmestoff, Caloricum". De fato, o éter permite tomar uma posição sobre o abismo que subsiste entre a Metafísica da natureza e a Física:

Existe uma matéria espalhada como um continuum no todo do espaço cósmico, que o preenche penetrando de modo uniforme todos os corpos (que não é, por conseguinte, sujeito a nenhuma mudança de lugar); essa matéria, que chamamos éter ou calórico etc., não é um elemento hipotético (para explicar certos fenômenos) [...], mas pode ser reconhecida e postulada a priori como uma peça pertencente necessariamente à passagem $<$ Übergang $>$ dos princípios metafísicos da ciência da natureza à física. ${ }^{4}$

De que modo Kant pode demonstrar que o éter possui uma realidade objetiva e não uma existência simplesmente hipotética, visto que ele não pode se basear diretamente na experiência?

Com efeito, Kant sempre admitiu a existência do éter e do calórico desde seus primeiros escritos pré-críticos, especialmente em seu De Igne de 1755, contemporâneo de sua Teoria do céu. Esses dois temas são ligados, pois o fogo e o calor tinham um papel essencial na formação dos corpos celestes. Inicialmente Kant tinha se distanciado de Newton e aderido à concepção de fogo de Euler: segundo Newton, o fogo e o calor não são substâncias, somente fenômenos, pois os fenômenos térmicos se reduzem simplesmente à agitação de partículas que se caracterizam por movimentos vibratórios. Também, a própria chama é apenas uma transformação em "vapor luminoso" dos alimentos do fogo. Segundo Kant,

4 Kant, Opus postumum, Ak XXI, 218; tr. fr. F. Marty, Paris, PUF, 1986, p. 56. Cf. aussi Op. cit., Ak XXI, p. 594. Em uma outra passagem, KANT traduz em latim esta fórmula que expressa tão bem a intenção geral do Opus Postumum, cf. Ak XXII, 519-520; tr. fr. Marty, Paris, PUF, 1986, p. 116: "Transitus, a metaphysicis principiis ad physicam principia mathematica". É possível notar na passagem, que o latim de Kant não é exatamente correto, pois ele certamente não se releu. 
que não negava esse aspecto das coisas, todos esses fenômenos vibratórios seriam incompreensíveis se não se recorresse à existência do éter, isto é, a um fluído elástico capaz de transmitir de forma contínua as ondulações próprias aos fenômenos térmicos. No mais, esse papel de medium que tem o éter (ou "matéria elástica") permite compreender melhor os fenômenos da rarefação. Pois, segundo Kant, a propagação térmica nos corpos deveria acabar por produzir sua desagregação, se não guardássemos, pelo menos, a única teoria científica do calor. É aí que intervém a teoria euleriana revisada por Kant: se os corpos aumentam de volume se rarefazendo é porque a força repulsiva do éter que os compenetra se intensifica enquanto a força originária de coesão (a atração) continua imutável. No limite, a elasticidade do éter permite compreender a fusão dos corpos sólidos e mesmo a vaporização dos líquidos sob a ação do calor. Inversamente, o congelamento dos líquidos se explica pela diminuição da força repulsiva ${ }^{5}$.

$\mathrm{Na}$ época do De Igne, a existência do éter dizia respeito apenas a questões de física, enquanto que na época crítica, nos Primeiros princípios metafisicos da ciência da natureza de 1786, Kant lhe conferiu um valor puramente metodológico no sentido de que ele permitia consolidar a

5 Cf. Kant, Breve Esboço de algumas Meditações sobre o fogo, de 1755, texto do qual estão aqui traduzidos alguns excertos particularmente esclarecedores, Ak I, 372-377: "Seção I: PROPOSIÇÃO III: Os corpos sólidos, assim como os corpos fluidos derivam sua consistência não do contato imediato das moléculas, mas da matéria elástica que se interpõem uniformemente entre os constituintes. [...] PROPOSIÇÃO IV: Explicar os fenômenos dos corpos sólidos no meio da matéria já citada, por intermédio da qual os elementos dos corpos, embora distantes de todo contato mútuo, se atraem, contudo, reciprocamente. [...] COROLÁRIO GERAL: Assim então, todo corpo, se eu não me engano, é constituído de partes sólidas, reunidas pelo intermédio de certa matéria elástica, por uma ligação. As partículas elementares, embora distantes de todo contato mútuo, se entreatraem, graças à interposição desta matéria elástica, e se reúnem mais estreitamente de forma que isto não seria possível por um contato imediato. De fato, visto que o contato das moléculas mais esféricas possíveis só podem se dar em um ponto, seria infinitamente mais falho que a coesão que se exerce sobre toda a superfície. É então realmente por esta razão que é possível modificar a disposição dos elementos sem que a coesão seja afetada, e nós compreendemos facilmente também como os elementos podem se reaproximar uns dos outros e como o volume pode diminuir se esta matéria que assegura a ligação se retira um pouco dos interstícios; inversamente, se por si esta matéria aumenta, seja a quantidade, seja sua elasticidade, o corpo pode começar a aumentar o volume e as partículas podem se separar umas das outras sem que isto seja às custas da coesão. Estes são os pontos mais importantes sobre a teoria do fogo. [...]" 
filosofia dinâmica da natureza evitando o conceito de espaço vazio, todavia indispensável à filosofia mecanicista da natureza:

Não acharíamos impossível conceber uma matéria (tal como se representa, por exemplo, o éter) que preencheria todo seu espaço sem nenhum vazio [...]. No éter, devemos conceber a força repulsiva como infinitamente maior, em relação à força atrativa, que em todas as outras matérias que conhecemos ${ }^{6}$.

Esse conceito de éter é concebível, mas escapa à experiência, assim como aquele do espaço vazio.

Por outro lado, no Opus postumum, o conceito de éter ou de calórico não assume mais um papel nem em física nem em metodologia, mas unicamente um papel transcendental para assegurar a passagem $<$ Übergang $>$ dos princípios metafísicos da ciência da natureza à física.

A atitude de Kant consiste em determinar apagogicamente que o éter é: aquilo sem o qual o todo da experiência seria impossível. Com efeito, toda experiência é produzida pela afecção que produzem em nossa receptividade as "forças motrizes da matéria" (assim se exprime o último $\mathrm{Kant}^{7}$ ); mas, essas forças motrizes seriam pura e simplesmente impossíveis na ausência do éter ${ }^{8}$. O éter, no Opus postumum, assume, de alguma forma, o status de postulado da razão pura teórica e ainda mais, visto que ele pode mesmo ser considerado como tendo uma existência necessária sob o plano transcendental.

Essas considerações sobre o éter foram levantadas no começo à propósito do problema do vazio e da unidade das forças fundamentais. Com efeito, o vazio não tem lugar a parte subjecti na experiência, visto

\footnotetext{
6 Kant, Primeiros principios metafísicos da ciência da natureza, de 1786, II Dinâmica, Aviso Geral, Ak IV, 534; tr. fr. Pléiade t. 2, p. 453. Cf. também, Op. cit., IV Fenomenologia, Ak IV, 564; tr. fr. Pléiade t. 2, p. 491.

7 Kant, Opus postumum, Ak XXII, 359; tr. fr. F. Marty, Paris, PUF, 1986, p. 90: “A fisica é a ciência (systema doctrinale) do complexo (complexus) do conhecimento empírico das percepções, como forças motoras da matéria que afetam o sujeito, enquanto, ligadas em um todo absoluto, elas constituem um sistema nomeado experiência".

8 KANT reconhece que esta prova tem algo estranho, mas que ela é todavia inquestionável, cf. Op. cit., Ak XXI, 221-226.
} 
que não há hiato nem salto nesta (in mundo, non datur hiatus, non datur saltus). Então, aquilo que tomamos por vazio, $<$ nihil negativum $>$ deve ser preenchido pelo éter. Teria sido absurdo considerar que o espaço como forma a priori da intuição externa possa ser vazio, ou seja, que ela teria se coordenado no nada. De fato, o espaço que intuímos como vazio é preenchido pelo éter que torna assim possível toda a experiência e "torna sensível" o espaço puro, visto que este último não teria sido sem isso nada além de uma simples forma vazia. Kant é perfeitamente consciente que passa do espaço como forma a priori da sensibilidade (cujo estatuto é subjetivo e transcendental) ao espaço físico objetivo, saindo do quadro da primeira Crítica. Donde a nota que Kant julgou necessário acrescentar:

O espaço representado simplesmente como forma subjetiva da intuição dos objetos externos não é de modo algum um objeto externo e nesse sentido, nem cheio, nem vazio (predicados que pertencem às determinações do objeto, de que se fazem aqui abstração). Mas o espaço como objeto da intuição externa é ou um ou outro. - Como o não ser de um objeto da percepção não pode ser percebido, o espaço vazio não é um objeto de experiência possível. ${ }^{9}$

Esse medium que é o éter transmite a luz, o calor e o frio; ele é mesmo uma espécie de intermediário entre os indivíduos ${ }^{10}$.

Voltando à cosmologia, o éter ou calórico, que unifica a diversidade dos fenômenos em uma espécie de matéria primeira, estende-se ao infinito, visto que ele é por si "espalhado de forma constante e ilimitada no espaço $^{l l}$ ". Já sabíamos desde a primeira Crítica que o espaço e o tempo são infinitos ${ }^{12}$, mas, no momento, aprendemos que o éter espalhado no espaço cósmico infinito é também ilimitado. Com efeito, por sua própria natureza,

9 Kant, Opus postumum, Ak XXI, 552; tr. fr. F. Marty, Paris, PUF, 1986, p. 71.

10 Kant, Opus Postumum, Ak XXI, p. 560.

11 Kant, Opus postumum, Ak XXII, 551; tr. fr. F. Marty, Paris, PUF, 1986, p. 71.

12 A Opus postumum retorna muito a este assunto, com insistência, cf. par exemple: Ak XXII, 11-13, 16. Todavia, KANT afirma explicitamente que é impossível de se provar experimentalmente que o espaço é infinito, pois não existe experiência de infinito, cf. Ak XXII, 474-476; PUF, p. 100-102. 
o éter possui propriedades (classificadas em função das categorias) que fundam sua ilimitação: ele é imponderável (quantidade), incoercível (qualidade), destituído de coesão (relação) e inexaurível (modalidade). A incoercibilidade ou a incompreensibilidade do éter se dá pelo fato de que nada pode se opor à sua extensão, visto que ele penetra todos os corpos. A inesgotabilidade do éter, tanto por divisão como por composição, implica igualmente sua infinitude. É o mesmo caso de sua incapacidade de coesão, resultante de sua característica repulsiva, que o leva a se difundir por toda parte $^{13}$. Dito de outro modo, a infinitude do éter é provada a partir do fato de que nada no mundo poderia contê-lo para fechá-lo dentro de limites. Mas, como tudo que existe no espaço e tempo está imerso no éter, segue-se que o universo é infinito:

Há um mundo, um espaço, um tempo, e se falamos de espaços e de tempos, eles só são pensáveis como partes de um espaço e de um tempo. Esse todo é infinito, ou seja, nenhum limite do diverso nele é possível como limitação real $<$ real $>$, pois de outro modo o vazio seria um objeto sensível. ${ }^{14}$

A argumentação é curiosa, pois ela retoma em termos fisicos dessa vez algumas demonstrações da antítese que figuravam na Dialética com um estatuto transcendental. No mais, ao vocabulário de Kant falta um pouco de estabilidade, pois ele chama tanto esse Todo de o Universo, como de o Mundo. Ele havia, entretanto, tomado cuidado de precisar corretamente que o universo é infinito e que ele contém uma pluralidade infinita de mundos:

Há um Deus e um Universum. A totalidade, Pluralitas Mundorum, não é universorum (contradictio in objecto) ${ }^{15}$.

É claro que, quando Kant emprega o termo mundo no sentido de uma Ideia transcendental totalizadora, ele pensa antes de tudo no universo.

13 Cf. Kant, Opus postumum, Ak XXI, 215; tr. fr. F. Marty, Paris, PUF, 1986, p. 14-15.

14 Kant, Opus postumum, Ak XXII, 49; tr. fr. F. Marty, Paris, PUF, 1986, p. 184.

15 Kant, Opus postumum, Ak XXI, 37; tr. fr. F. Marty, Paris, PUF, 1986, p. 224; cf. também Ak XXI, 33; PUF, p. 221. 
É então por sinédoque que o mundo pode designar o universo ${ }^{16}$.

\section{A Cosmoteologia transcendental ou os dois infinitos e o papel do calórico}

É especificamente o caráter abrangente e totalizante das Ideias de Universo e de Deus que permitem a Kant estabelecer uma espécie de paralelo entre esses dois objetos da filosofia transcendental, pois, tanto um como o outro fazem intervir no pensamento a Ideia de Maximum e de infinitude:

Deus e o mundo [...] são um máximo, aquele segundo o grau (qualitativamente) e o outro segundo o que compreende de espaço (quantitativamente), de modo determinado, um como objeto da razão pura, o outro como objeto sensível. Ambos são infinitos; o primeiro como grandeza do fenômeno no espaço e no tempo, o segundo de acordo com o grau (virtualiter) como atividade sem limite, no que diz respeito às forças (grandeza matemática ou dinâmica dos objetos sensíveis) - Um como coisa em si ou fenômeno. ${ }^{17}$

Mesmo que a redação não seja sempre rigorosa, essa passagem diz muito sobre a evolução de Kant. Certamente, do ponto de vista da definição, nada encontramos de surpreendente em relação à primeira Crítica, sobretudo em matéria de Teologia. Ao contrário, ficamos muito surpresos em ver que o nosso filósofo não tem mais nenhuma dificuldade em afirmar a infinitude do universo ${ }^{18}$. Ele parece ter esquecido todas as reservas feitas na Antinomia e, para melhor compreender a infinitude

16 Os linguistas chamam "sinédoque" (ou mesmo uma metonímia) a figura do discurso que toma a parte pelo todo.

17 Kant, Opus postumum, Ak XXI, 11; tr. fr. F. Marty, Paris, PUF, 1986, p. 197. Cf. também, Ak XXII, 54; PUF, p. 188.

18 Kant, Opus postumum, Ak XXI, 35; tr. fr. F. Marty, Paris, PUF, 1986, p. 222: "O mundo universum. Se o mundo tem limites, isso equivale a se perguntar se o espaço tem limites; pois este não pode ser designado por nenhum objeto determinando os sentidos. [...] Em se tratando de mundos, são apenas massas, ou seja, partes limitadas de matéria estendida ao infinito, ocupando o espaço (corpora)". 
atual do universo, ele a compara com aquela que implica a ideia de Deus (distinguindo bem o plano da qualidade e aquele da quantidade). A partir de agora o que conta em Cosmologia já não é a ideia de série, mas sim aquela de totalidade. Também, o mundo tomado como um Maximum, ou seja, como uma totalidade infinita, não poderia ser concebido de outro modo senão existindo em ato, ao menos no que diz respeito à sua extensão espacial, do contrário, não estaríamos nos referindo a uma verdadeira totalidade acabada. Do mesmo modo, se o Mundo fosse uma totalidade fechada (ou finita) existente em ato, não teríamos como nos referir a um Maximum. O que é novo no paralelo que o nosso filósofo estabelece aqui, é que isso não é inferido por uma espécie de relação de expressão (como era ainda o caso da tradição metafísica segundo a qual a grandeza do mundo expressa necessariamente a glória de Deus); isso decorre de uma simples comparação entre as determinações das duas Ideias. Essas reflexões que pensam conjuntamente Deus e o Universo - sem jamais os confundirem - concernem ao que Kant chama de cosmoteologia transcendental ${ }^{19}$. Ora, tudo se passa como se o nosso filósofo tivesse permanecido, toda a sua vida, indefectivelmente apegado à infinitude cósmica, ao menos tal é a nossa conjectura. Todavia, Kant teria rejeitado momentaneamente a afirmação de infinitude do universo, na época da publicação das três Críticas: $1^{\circ}$ ) para evitar a devastação desastrosa que um certo infinitismo, mal compreendido, pudesse causar na moral e na religião, $2^{\circ}$ ) para evitar a armadilha do panteísmo tanto denunciado na ocasião do "Pantheismusstreit". Para sustentar nossa interpretação, é preciso reconhecer que, se as armações do Opus postumum constituem apenas um vasto canteiro a ser trabalhado, apenas uma espécie de laboratório de ideias, onde não se encontra nenhuma demonstração da finitude do universo, isso assim se daria apenas a título de hipótese destinada a colocar à prova o infinitismo das antíteses. Apenas encontramos sobre esse assunto advertências muito importantes a fim de não confundir Deus com o Universo, ou seja, precauções intelectuais destinadas a evitar que o infinitismo cosmológico não leve a um panteísmo

19 Cf. por exemplo, Kant, Opus postumum, Ak XXI, 24; tr. fr. F. Marty, Paris, PUF, 1986, p. 210: "Não existem deuses, mais que mundos, mas um Deus e um mundo. Cosmologia transcendental e teologia transcendental (cosmoteologia).". 
de tipo espinosista:

A pluralidade dos mundos (pluralitas mundorum) significa apenas a multiplicidade de vários sistemas, de que pode haver uma quantidade indizível. [...] Deus não é um habitante do mundo, mas seu possuidor. Se Ele fosse um habitante do mundo (como ser sensível), Ele seria a alma do mundo que pertence à natureza. ${ }^{20}$

A cosmologia infinitista volta então com força no Opus postumum, pois ela parece livre das dificuldades que tinham conduzido a primeira Crítica a qualificar seu objeto de ilusão transcendental. Não esqueçamos que Kant mencionou repetidamente no seu último trabalho inédito que o plano geral da obra deveria ser dividido em duas partes, cuja primeira seria um Sistema dos Elementos e a segunda um Sistema do Mundo, visto que o éter seria encarregado de assegurar a passagem de uma a outra:

A matéria imponderável, difusa em todo o espaço cósmico $<$ Weltraum $>$ [...] substância hipotética [...] constitui a passagem $<\ddot{\text { Ubergang }>}$ do sistema elementar <Elementarsystem $>$ ao sistema do mundo $<$ Weltsystem $>21$.

Assim, a questão que se põe é saber qual era então a cosmologia que deveria expor essa segunda parte do sistema do Übergang, já que Kant morreu antes de ter conseguido expor integralmente seu <novo $>$ Weltsystem. De fato, não é certo que ele teria integrado o sistema do mundo de Laplace no seio de sua própria cosmologia, contrariamente àquilo que pretendia Charles Andler ${ }^{22}$. Certamente, é verdade que encontramos no

20 Kant, Opus postumum, Ak XXI, 30; tr. fr. F. Marty, Paris, PUF, 1986, p. 218. Kant repete esta advertência para reafirmar a transcendência divina, Ak XXI, 33; PUF, p. 220: "[Deus] não é a alma do mundo (anima mundi), não é um espírito do mundo (spiritus), não é um demiurgo, como contratante subordinado". Do mesmo modo, lemos em Ak XXI, 18; PUF, p. 205: "Não que o mundo seja Deus ou Deus um ser no mundo (alma do mundo)".

${ }^{21}$ Kant, Opus postumum, Ak XXII, 598. Nós encontramos a mesma idéia Op.cit., Ak XXI, 359; PUF, p. 33 et Ak XXII, 550; PUF, p. 70.

22 Charles Andler et Chavannes, Primeiros princípios metafísicos da ciência da natureza, Paris, Alcan, 1891, p. LXXXV. 
Opus postumum uma menção à obra de Laplace de próprio punho: " $L a$ Place Weltsystem ${ }^{23}$ ", mas isso não foi suficiente para poder concluir que ele teria integrado este último em seu próprio sistema, sem a mínima crítica ou a mínima modificação de um ou de outro. Uma única coisa é certa, Kant concebe a formação dos planetas e dos diferentes corpos celestes em seus últimos escritos de uma forma análoga àquela que havia desenvolvido na segunda parte da Teoria do céu:

Que todos os corpos celestes que conhecemos no nosso sistema solar giram em torno de seu eixo do leste para o oeste [...] esse mecanismo resultou na formação dos planetas, da matéria que formou o próprio sol e que produz a rotação axial nessa direção; mas que os satélites dos planetas nesse caso apresentem sempre o mesmo lado para o planeta principal, como a Lua à Terra, e que eles realizam sua rotação com a mais extrema exatidão precisamente no mesmo tempo que sua revolução periódica [...] isso parece ter por causa eficiente que cada satélite foi formado a partir de um elemento como o anel de Saturno, e o próprio anel, a partir das partículas de uma atmosfera [...] que levou a uma superfície, cujas partículas em parte caíram no núcleo e, em parte, formaram as luas, como satélites e planetas afiliados ${ }^{24}$.

A formação do anel de Saturno permanece sempre um modelo epistemológico exemplar que permite a Kant explicar a formação dos planetas e dos satélites, do sistema solar e mesmo da estrutura da Via Láctea e de outras galáxias. Tudo o que nos importa destacar nesse momento no

23 KAnt, Opus postumum, Ak XXI, 625. Esta folha foi datada por especialistas entre dezembro de 1798 e janeiro de 1799. A primeira edição da Exposição do sistema do mundo de LAPLACE é de 1796 e a segunda de 1799. Kant pode ler ou percorrer a Exposição de Laplace na introdução alemã de Johann Karl Friedrich Hauff, em dois volumes, publicados a partir de 1797 em Francfort-sur-le-Main na editora Warrentrapp et Wenner: Darstellung des Weltsystems durch Peter Simon La Place, Mitglied des französischen Nationalinstitus und Commission wegen der Meereslänge. Na ausência de documentos, é impossível forçar a conjectura. AdicKes nota em seu Kant als Naturforscher, Berlin, 1924-1925, tome 2, p. 309, que "Kant não mais defende, no Opus Postumum, toda sua própria cosmogonia assim relacionada àquela de Laplace, como ela está contida na Teoria do Céu de 1755: a evolução do mundo é definitivamente abandonada ao curso do resfriamento".

${ }^{24}$ Kant, Opus postumum, Ak XXII, 5-6; tr. fr. F. Marty, Paris, PUF, 1986, p. 123-124. Este importante texto remonta a um período que AdICKes situa nos idos da primavera de 1800 . 
Opus postumum são as diferenças mais importantes com as concepções da Teoria do céu e com as da Antinomia que denotam o sentido de evolução do pensamento kantiano em matéria de Cosmologia.

Primeiramente, é impressionante ver que Kant respeita sempre bastante os ensinamentos da Analítica Transcendental, ao passo que ele retorna longamente aos objetos da Dialética transcendental sem se ater verdadeiramente às advertências da Antinomia ${ }^{25}$. Se ele tivesse permanecido fiel às conclusões da Antinomia, que significaria então a adoção deliberada do ponto de vista infinitista em cosmologia, que aparece repetidamente nos comentários do Opus postumum? Não seria antes o sinal de que Kant mudou de posição em relação ao próprio estatuto da Cosmologia? A forma mais "enfraquecida" da nossa interpretação, e então a mais prudente, consistiria em dizer que Kant volta, simplesmente a título de esboço ou de ensaio, aos desenvolvimentos cosmológicos (infinitistas) da época pré-crítica, na esperança de nela encontrar os elementos para realizar o Übergang. Mas, mesmo nos posicionando nessa perspectiva "prudente", é impressionante constatar que o próprio Kant, não mostra nenhuma cláusula de prudência, pois não hesita em afirmar abertamente não apenas a infinitude do universo (o que poderia ter sido apenas uma simples hipótese de trabalho) mas, ademais, sua absolutidade, o que se torna inadimissível aos olhos de um leitor da primeira Crítica:

Podemos apenas começar pela totalidade das coisas, como uma unidade sintética absoluta (cujo fenômeno $<$ Phänomen $>$ é espaço e tempo). Nela é possível a determinação completa a priori, e essa é a existência do mundo. Se falamos de mundos, esses são apenas sistemas diversos de um mundo num todo absoluto, que todavia é ilimitado; pois o espaço vazio não é um objeto $<$ Object $>$ dos sentidos, não é uma coisa (non est ens) sem ser todavia um não ser (non ens),

25 Nós poderíamos citar, apesar de tudo, alusões muito excepcionais à Antinomia, que aparece no Opus Postumum, mesmo que elas não façam de fato referência à Ideia cosmológica, mas aos objetos transcendentais em geral. cf. Ak XXI, 75; tr. fr. F. Marty, Paris, PUF, 1986, p. 289: "Se o limite da filosofia transcendental é cruzado, o pretenso princípio se torna transcendente; isto é, o objeto $<$ Object $>$ se torna um não ser e seu próprio conceito se contradiz; pois ele cruza a fronteira de todo saber: a palavra pronunciada é vazia de sentido". 
ou seja, alguma coisa que se contradiga ${ }^{26}$.

Tudo se passa como se a mudança fundamental que ocorre na cosmologia do Opus postumum e que lhe permite exceder ao mesmo tempo as concepções da Teoria do céu e as reservas expressas da primeira Crítica, residia na adoção do éter ou do calórico, que desempenha então papel determinante no Übergang. O éter é, com efeito, o ponto de chegada da filosofia transcendental, enquanto condição suprema da possibilidade da experiência ${ }^{27}$, e o ponto de partida do sistema inteiro da Física, visto que é o princípio universal de todo movimento ${ }^{28}$; é então ele a interface que realiza o Übergang e que permite a passagem, como diz o próprio Kant: do "sistema elementar ao sistema do mundo ${ }^{29 "}$. Compreendemos desde então porque Kant, que atribuía apenas um papel técnico ao calórico em 1786, na época de seu artigo sobre os Vulcões lunares, the atribui agora uma importância filosófica fundamental: vê nele um meio de completar o sistema inteiro da filosofia transcendental. Ora, acontece que a adoção do Éter ou do Calórico não deixa de infletir um pouco o sentido de toda a filosofia transcendental. Com efeito, o éter tem um papel unificador inteiramente comparável (no plano físico) à função que assegurava o sujeito transcendental ou a "apercepção transcendental" no campo do conhecimento, ou seja, uma unificação formal com relação às representações e às categorias ou funções de ligação do intelecto puro. Do mesmo modo que o Ich denke é qualificado como apercepção originária, o calórico também é um "elemento originário [...] originalmente motor

\footnotetext{
26 Kant, Opus postumum, Ak XXII, 96; tr. fr. F. Marty, Paris, PUF, 1986, p. 163.

27 Kant, Opus postumum, Ak XXII, 554; tr. fr. F. Marty, Paris, PUF, 1986, p. 74: “O calórico é real porque seu conceito (com os atributos que nós atribuímos à ele) torna possível o conjunto da experiência[...] é imediatamente dado pela razão para fundar a possibilidade da própria experiência“" Cf. também, Ak XXI, 549 sg., tr. fr. Gibelin, p. 103: "O calórico que tudo penetra é a primeira condição da possibilidade de experiência”.

28 Kant, Opus postumum, Ak XXII, 224; tr. fr. F. Marty, Paris, PUF, 1986, p. 61: "A base do todo da unificação de todas as forças motoras da matéria é o calórico (ao próprio modo do espaço hipostasiado, no qual tudo de move), o principio da possibilidade de unidade do todo da experiência possível. [...] Assim, esta matéria é difundida por todo o edifício do mundo, e sua existência é necessária, especificamente em relação aos objetos dos sentidos".
}

29 Kant, Opus postumum, Ak XXII, 550; tr. fr. F. Marty, Paris, PUF, 1986, p. 70. 
[...] a base do todo da unificação das forças motrizes da matéria. [...] Essa matéria é espalhada por todo o edifício do mundo". ${ }^{30} \mathrm{O}$ calórico constitui assim o correlativo empírico do sujeito transcendental, visto que, tanto um como outro, não poderiam ser "devirados" e que eles conferem, cada um de maneira diferente, uma unidade originária, respectivamente, à multiplicidade das representações da consciência ou à diversidade dos movimentos da matéria. Kant se detém tanto na introdução do calórico no Übergang que ele até mesmo pensou, numa importante passagem, fazer dele objeto de um teorema, que ele enuncia como segue, de maneira particularmente condensada, antes de fornecer a prova sobre um modelo evidentemente apagógico:

\section{Teorema}

As matérias originalmente motrizes pressupõem um elemento que preenche, penetrando todo o espaço cósmico, como condição da possibilidade da experiência das forças motrizes nesse espaço; esse elemento originário, pensado não como hipotético para a explicação dos fenômenos $<$ Phänomene $>$, mas como elemento categoricamente demonstrável a priori pela razão, está contido na passagem dos princípios metafísicos da ciência da natureza à física ${ }^{31}$.

A prova a priori do teorema consiste em fazer valer, de um lado, a ideia de que uma experiência do movimento no espaço vazio é inobservável e se reduz a algo sem sentido; de outro lado, o movimento de translação em um espaço cheio é impossível. Por conseguinte, é preciso que o espaço físico (ou material, como diz Kant) seja um meio penetrável para os corpos em movimento, o que não pode ter lugar senão se o dito espaço está preenchido de éter, c.q.d ... Compreendemos melhor agora que o calórico ou o éter seja um elemento que interessa às vezes à Filosofia (pois acaba por completar utilmente a Estética transcendental fornecendo um correlato objetivo à forma pura do sentido externo: um "espaço

30 Kant, Opus postumum, Ak XXI, 223-224; tr. fr. F. Marty, Paris, PUF, 1986, p. 60-61.

31 Kant, Opus postumum, Ak XXI, 223; tr. fr. F. Marty, Paris, PUF, 1986, p. 60. 
perceptível"32) e as vezes à Física (unificando a diversidade dos fenômenos em um elemento primordial e real, um continuum físico que já não envolve princípio imaterial, como era ainda o caso do sensorium Dei de Newton e de Samuel Clarke).

Todavia, no seu teorema, Kant tomou o cuidado de distinguir o plano da Física, em que o éter só é admitido a título hipotético para explicar os fenômenos, e o plano da filosofia transcendental, em que sua existência é "categoricamente demonstrável a priori pela razão". Essas duas modalidades distintas para a existência do éter são aparentemente paradoxais e necessitam de uma justificação precisa. Primeiramente é totalmente compreensível que o éter não tenha obtido na Física (isto é, tomado "diretamente"), senão um valor hipotético, uma vez que ele escapa a toda experimentação possível e serve somente para unificar as forças motrizes enquanto poderia bem ser o seu fundamento originário. Todavia, Kant reconhecia que o éter não possui nele mesmo as propriedades que confere aos fenômenos que permite explicar: ele permite entender a elasticidade sem ser ele mesmo elástico, assim como permite entender os fenômenos de coesão, ainda que não seja dotado de coesão, e o mesmo ocorre no tocante à fluidez etc. Compreendemos nesse sentido que Max Planck tenha afirmado mais tarde a esse respeito que o éter foi realmente "o filho rebelde da teoria mecânica ${ }^{33}$ ", pois todas as determinações que a filosofia mecânica tentou dar ao éter foram infelizmente contraditórias. Kant, então, não se ilude sobre o caráter hipotético do éter em Física, visto que reconhecia que esse não é senão um "ser de razão <ens rationis>”, no sentido de um "ser em pensamento $<$ Gedankending $>$ 34", que não constitui propriamente falando um conhecimento, mas um elemento simplesmente hipotético. Seria ilegítimo na Física fazê-lo alguma coisa a mais do que uma hipótese.

Em contrapartida, para a filosofia transcendental, é impossível passar sem o éter, visto que constitui não uma condição de possibilidade

\footnotetext{
32 KAnT, Ibid., Ak XXI, 224; tr. p. 61.

33 Max Planck, Die Stellung der neuen Physik zur mechanischen Weltanschauung, Verh. Der Ges. dtsch. Naturf. u. Ärzte in Königsberg, 1910, Leipzig, 1911, p. 64 sg.

34 Kant, Opus postumum, Ak XXII, 606.
} 
de tal ou qual fenômeno físico, mas a condição suprema da unidade de toda experiência possível. Nesse sentido, o éter pode ser posto categoricamente, mas somente de maneira indireta, para realizar a unidade das condições formais e materiais de toda experiência. Dito de outro modo, o caráter indireto dessa demonstração a priori da existência do éter é que ele é aquilo sem o que nenhuma experiência poderia ser completamente determinada.

O éter ou o calórico "sensibiliza", ou melhor, confere um correlato físico ao espaço puro e a priori do sentido externo, exorcizando o espectro da extensão infinita considerada como uma propriedade resultante da onipresença divina. Nesse sentido, a solução kantiana para o problema do Übergang evita assim um salto transcendente ou ilegítimo no suprassensível.

Todavia, ao fazer repousar essa solução sobre o conceito de éter, Kant toma para sua filosofia uma orientação cosmológica muito marcada, que põe em questão, ao menos parcialmente, o sentido e o alcance de toda a Antinomia da primeira Crítica. Esse deslocamento nos últimos desenvolvimentos de Kant em direção a uma Cosmologia infinitista renovada, ou, ao menos, cuja refundação estava em curso, é o sinal de uma evolução epistemológica importante, que já não teme a ruína da filosofia prática e nem teme prejudicar a religião, mas que tenta unir ainda mais estreitamente a filosofia teórica e prática. Resta-nos então examinar, em um último momento, como Kant considerava, nesta nova perspectiva, as relações de Deus, do Mundo e do homem em uma cosmoteologia renovada pela solução do Übergang. Notaremos, enfim, que Kant já não desce da filosofia transcendental à Física, mas opera um retorno ascendente da metafísica das ciências da natureza à filosofia transcendental.

\section{As três ideias totalizadoras: o mundo, o homem e Deus}

Estamos lidando, segundo a datação de Adickes, com os últimos delineamentos do Opus Postumum, que se estende entre abril de 1800 e os primeiros meses do ano de 1803 . Se, todavia, essa datação não for inteiramente certa, trata-se em todo caso dos últimos desenvolvimentos do Opus Postumum segundo a ordem lógica. Com efeito, para completar a sua filosofia transcendental, Kant dirige toda a sua atenção para as ideias totalizadoras de Deus e do Mundo, procurando elucidar os tipos 
de relações suscetíveis de religá-las em uma síntese unificadora última. Essa preocupação arquitetônica do último Kant é interessante, pois ele põe em relação as ideias transcendentais que a Dialética tinha abordado de maneira separada (mesmo se existisse no espírito de Kant uma espécie de progressão, ao menos implícita, da idéia de alma àquela do mundo, e então à de Deus, cujo "conceito termina e coroa todo conhecimento humano ${ }^{35}$ "). Assim, lemos esta nota na margem do Opus Postumum: "Deus e o mundo não são seres coordenados um com o outro, mas o segundo é subordinado a o primeiro ${ }^{36 " . ~ A i n d a ~ r e s t a ~ o r d e n a r ~ e s s a s ~ i d e i a s ~ p a r a ~ q u e ~ e l a s ~ f o r m e m ~}$ um sistema, mas veremos que, após várias tentativas de síntese, Kant, portanto, renuncia a subsumir as ideias transcendentais sob aquela de Deus, mas lembra que é o próprio homem, como pensante e agente segundo o imperativo categórico, que opera a ligação entre as duas outras Ideias. Kant não abandona de modo algum seu idealismo crítico, concluindo o Übergang por um retorno às ideias transcendentais. Aliás, apenas segue o plano do Opus que tinha traçado expressamente, ao anunciar que o "Übergang" permite passar do sistema elementar ao sistema do mundo: "Primeira parte: do sistema elementar da matéria (por análise); segunda parte: do sistema do mundo ${ }^{37}$ "

Como já tinha estabelecido claramente a primeira Crítica, o sistema é a forma da ciência; mas o Opus quer ir mais longe do que a Dialética transcendental e que a Arquitetônica para acabar o sistema da filosofia transcendental cuja Crítica era apenas uma propedêutica à ciência. Por isso, Kant insiste na importância do sistema das ideias transcendentais:

A filosofia transcendental é a consciência da faculdade do sistema de ser autor das idéias de um ponto de vista teórico tanto quanto prático. [...] Ela é a ciência do filosofar sobre a filosofia, como um sistema de princípios sintéticos a priori a partir dos conceitos. [...] Ela não é um complexo, agregado, de filosofemas, mas o princípio de um sistema de

\footnotetext{
35 Kant, Critique de la raison pure, Ak III, 426; tr. fr., Paris, Pléiade, t. 1, 1980, p. 1246.

36 Kant, Opus postumum, Ak XXII, 117; tr. fr. F. Marty, Paris, PUF, 1986, p. 170.

37 Kant, Opus postumum, Ak XXI, 359; tr. fr. F. Marty, Paris, PUF, 1986, p. 33. Cf. também, Ak XXII, 598.
} 
Idéias que compreende tudo, idéias que constituem a filosofia como todo absoluto (não relativo) dos princípios do filosofar ${ }^{38}$.

A questão é saber como totalizar os seres cujas Ideias temos em nós. Kant até mesmo pensou uma vez em caracterizar a filosofia como uma "Pantologia", na medida em que ela é um esforço de totalização do saber e da sabedoria:

A divisão Deus e mundo é lícita? Todo saber é a) ciência; b) arte; c) sabedoria (sapientia, sophia). A última é simplesmente o que é subjetivo. Possuir a sabedoria, conhecer a sabedoria, ser sábio. A fisiologia, cosmologia, todo do mundo; teologia, teleologia, antropologia, Pantologia, o todo dos seres ${ }^{39}$.

Nessa perspectiva, a Pantologia inclui a cosmologia, a antropologia e a teologia, como o gênero subsume a espécie; mas está claro nesse nível que Kant se interessa mais pela totalidade dos seres que pelo próprio ser. Ainda seria preciso determinar mais precisamente as relações internas que mantêm no seio da Pantologia essas três totalidades particulares, que são o mundo, o homem e Deus. De fato, Kant procura unificar no todo da filosofia transcendental o sistema das Ideias, cuja pluralidade ainda causa problema; mas, em caso algum, nosso filósofo quer incorrer em uma espécie de monismo (de tipo espinosista) que absorveria a totalidade dos seres no Ser da totalidade, isto é, Deus como substância única ${ }^{40}$. Por outro lado, apesar das belas páginas da Metodologia da faculdade de julgar teleológica da terceira Crítica, Kant não procura de modo algum na finalidade natural um meio filosófico para passar do mundo a Deus, pois isso implicaria um salto transcendente para se elevar da matéria em direção a um princípio imaterial e pensante, autor inteligente da dita finalidade:

\footnotetext{
38 Kant, Opus postumum, Ak XXI, 93; tr. fr. F. Marty, Paris, PUF, 1986, p. 232.

39 Kant, Opus postumum, Ak XXI, 6; tr. fr. F. Marty, Paris, PUF, 1986, p. 262.

40 Numerosas são as referências à Spinoza no Opus Postumum, onde Kant pensa encontrar uma forma de idealismo transcedental (curiosamente), mas em nenhum momento ele se deixou ser tentado pelo monismo do autor da Ética. Na Crítica da faculdade de julgar, §, Ak V, 439-440, KANT tinha expressamente se separado do panteísmo de Spinoza, como ele já o tinha feito em seu famoso artigo publicado na Berlinische Monatschrift em 1786 sob o título: $O$ que é se orientar no pensamento?
} 
Se o princípio imaterial, que é a causa dos corpos orgânicos e que só pode ser pensado como um princípio de fins, é um ser pensante, e se lhe convém personalidade, e mesmo absolutamente a singularidade, e em seguida o predicado da divindade, isso não pode ser decidido pela filosofia transcendental. - A matéria com sua finalidade constitui um edifício do mundo. Unidade de espaço (sem limite), unidade da atração segundo Newton. - Aquela da repulsão pela luz e pela penetração. "Calórico"41.

É instrutivo seguir as diversas tentativas kantianas para unificar as três ideias tradicionais da metafísica, especialmente na Anotação I, 1-3, cuja redação remonta provavelmente a 1800 e 1801, segundo a datação de Adickes. Uma clara tendência se desenha, que oferece uma solução finalmente bastante próxima da terceira Crítica. Com efeito, depois de ter procurado alternativamente a síntese final na teologia, em que Deus seria o Urgrund de que derivariam o mundo e o homem, e depois na cosmologia, com os riscos dos panteísmos já evocados e que ele queria a todo preço evitar, Kant se encaminhou para a ideia de que é ao homem que cabe operar a síntese última, já que ele pertence ao mesmo tempo ao sensível e ao suprassensível. É nesse sentido que Kant qualifica o homem de Cosmotheoros, enquanto ele é um habitante e um espectador do universo que liga, graças ao seu estatuto de ser pensante, o Mundo (ou o universo) a Deus:

Deus, o mundo e o homem, um ser sensivelmente prático no mundo (arquitetonicamente), Cosmotheoros, que cria ele mesmo a priori os elementos do conhecimento do mundo, a partir dos quais constrói na Idéia a concepção do mundo permanecendo ao mesmo tempo como habitante do mundo ${ }^{42}$.

O Cosmotheoros de Huygens, publicado de maneira póstuma em 1698, era bem conhecido de Kant, que já o havia mencionado várias vezes a partir de 1755 em sua Teoria do céu $u^{43}$, mas ele confere um novo significado

41 Kant, Opus postumum, Ak XXI, 100; tr. fr. F. Marty, Paris, PUF, 1986, p. 239.

42 Kant, Opus postumum, Ak XXI, 31; tr. fr. F. Marty, Paris, PUF, 1986, p. 219. Kant retoma este termo de Huygens et o emprega diversas vezes na Opus Postumum, cf. por exemplo, Ak XXI, 100, tr. Marty p. 239-240.

43 Cf. por exemplo Kant, Teoria do céu, Ak I, 252. É verdade que o Cosmotheoros de 
a esse conceito no Opus postumum, pois se trata do Homem tomado como Maximum, isto é, como ideal ${ }^{44}$. Esse cosmotheoros como "homem ideal" é ao mesmo tempo um ser pensante e um ser pensado: é ao mesmo tempo Ideia transcendental de Homem (portanto; Homem em pensamento) e também o homem pensante portador das Ideias transcendentais neste mundo. Assim, o arco se fecha sobre o cosmotheoros, porque ele é ao mesmo tempo um habitante do Mundo e um ser pensante assediado pela Ideia de Deus. Kant acrescenta que se houver um caráter comum que reúne esses três objetos da filosofia transcendental, ainda que tome uma acepção específica em cada um dos casos, esse é sua infinitude: "Deus, o Mundo e a vontade livre do ser racional no Mundo. Todos são infinitos ${ }^{45 "}$. Por isso, Kant insiste tanto no aspecto ético-prático e no imperativo categórico que demonstram indiretamente, é verdade, que o Homem é neste mundo o único ser livre capaz de operar a síntese da natureza e da liberdade, mas essa síntese é simplesmente pensada como Ideia. Aí se encontra ainda o sentido de seu idealismo transcendental ${ }^{46}$, mas vemos doravante, talvez mais claramente do que na terceira Crítica, como a filosofia teórica e a filosofia prática são projetadas como indissociáveis nessa síntese ${ }^{47}$.

Data de registro:24/05/2013

Data de aceite: 08/07/2013

\footnotetext{
Huygens era uma obra que foi traduzida em quatro línguas e conheceu doze edições entre 1698 e 1767 !

44 Kant, Opus postumum, Ak XXI, 94; tr. fr. F. Marty, Paris, PUF, 1986, p. 233: “Os seres devem ser pensantes que, ainda que eles existam somente nos pensamentos do filósofo, possuem nesses aqui, todavia, uma realidade $<$ Realität $>$ ética-prática. Elas são Deus, o todo do mundo, e o homem no mundo submetido segundo o conceito de dever ao imperativo categórico (que é por conseguinte princípio de liberdade). Estes objetos não se remetem somente a ideais, o que quer dizer que cada um deles seja um maximum, e eles também se remetem a coisas que estão fora de nós".

45 Kant, Opus postumum, Ak XXI, 37; tr. fr. F. Marty, Paris, PUF, 1986, p. 224.

46 Kant determina um pouco esse tema escrevendo, in $O p$. cit., Ak XXI, 34, 37, tr. fr. F. Marty, Paris, PUF, 1986, p. 221, 223: “Deus, o Mundo e o sujeito ligando os dois objetos, o ser pensante no Mundo. Deus, o Mundo e aquele que reúne os dois em um sistema, o princípio pensante do homem (mens) habitando no mundo. [...] Deus, o Mundo e eu, o sujeito pensante no Mundo, que os junta. [...] É o homem pensante, o sujeito que os liga em proposição".

47 Tradução: Maiara Batalini de Macedo e Marina Batalini de Macedo.
} 